\title{
Clinton pledges to smooth path of research at universities
}

[WASHINGTON] President Bill Clinton pledged last week to "renew the alliance between America and its universities". He endorsed an action plan produced by his administration which, he says, will attract more women and minorities into science, "cut down the red tape" confronting researchers and clarify the status of graduate students.

"America's scientists should spend more time on research, not filling out forms in triplicate," said Clinton. He was speaking at a ceremony where he presented national medals of science and technology to scientists, engineers and corporations.

He has accepted a plan proposed by his National Science and Technology Council (NSTC), a committee of all the main science administrators in the federal government. This follows a three-year study of trouble spots between universities and government.

"We must move past today's patchwork of rules and regulations and develop a new vision for the university-federal government partnership," he said.

The NSTC promises that government science agencies will agree on changes to "reduce differences" in the way they administer research grants, and implement them within 12 months. This should make it easier for researchers to apply for funding to different agencies without repeating themselves.

The plan also promises to streamline requirements for grant recipients to certify that they meet certain legal standards, such as providing a workplace free of recreational drugs. Changes could enable certification to be obtained on an institution-wide basis, says NSTC, greatly reducing paperwork.

The study acknowledges the extensive ad hoc demands for cost-sharing with the universities that some federal agencies are placing on grant recipients - to the alarm of universities. It promises to get agencies to state clearly what their policies are on costsharing, again within 12 months.

And the NSTC promises to review policies under which some parts of the government, notably the Internal Revenue Service, refuse to accept the status of graduate students as both employees and students.

However, the NSTC study calls for more talk — particularly with the universities rather than for specific action to be taken now to tackle any of these problems. Similarly, a memo issued by Clinton in response to the study calls for recommendations to be developed within 12 months, rather than ordering immediate changes in policy.

Still, the universities hailed the proposals and Clinton's endorsement of them. "We

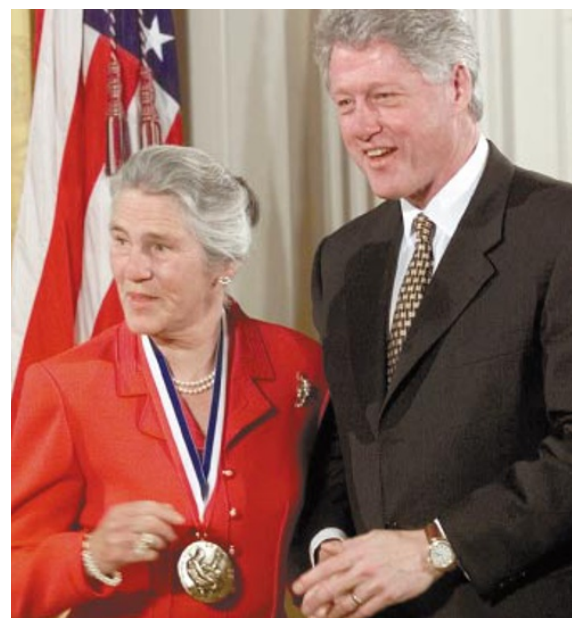

Clinton awards cancer researcher Janet D. Rowley a national science medal at last week's ceremony.

welcome the fact that the president of the United States has placed this on his agenda," says Nils Hasselmo, president of the American Association of Universities, which represents 50 leading research universities.

Especially helpful, says Hasselmo, are the promises to clarify the status of graduate students and to spell out policy on cost-sharing.

"Cost-sharing too often becomes a matter of negotiation between the programme director and the principal investigator, and that has raised grave concerns," he says. "We want to make cost-sharing fair and effective, as well as transparent."

The administration plans half a dozen public hearings around the country, starting

in Washington at the end of this month, to discuss its proposals with university administrators and researchers.

But some observers, while welcoming the ambitious scope of the review, worry that it is taking place too late in Clinton's second term to lead anywhere. "It has some potential if the administration stays focused on it," says one official familiar with universitygovernment relations. "If Al Gore is elected in 2000, maybe it will carry over."

During the award ceremony last week, Clinton offended Republican members of the House Science Committee by calling Rush Holt (Democrat, New Jersey), a physicist who was elected to the Congress last November, "the only bona-fide scientist in the US Congress". "It is about time we had one and I'm glad he's here," added the usually well-briefed president.

His remark wounded at least two Congressmen who had been working on science issues for years before Holt's election. Vernon Ehlers (Republican, Michigan), who has just written a National Science Policy Study for the Congress, is a former physics professor; Roscoe Bartlett (Republican, Maryland) is a physiologist and inventor with 100 published papers and 20 patents to his name.

"These two fine leaders might not have created the Internet," said James Sensenbrenner (Republican, Wisconsin), chair of the Science Committee, in a reference to Vice-President Al Gore's recent paternity claim on the medium. "But in my book they are bona-fide scientists.”

Colin Macilwain

\section{UK failing to reap neuroscience rewards}

[LONDON] British companies are failing to reap substantial commercial benefits from neuroscience, even though British research is the second most cited in neuroscience patents in the United States, according to a 12-country audit of such research just published by the Wellcome Trust.

The audit reveals that, although 13 per cent of inventors named on US neuroscience patents are British, only 3.5 per cent of these patents are owned by British individuals or companies. Ownership is dominated by US industrial corporations.

The audit says this 'exploitation gap' in neuroscience - a generic problem in UK academic research - needs to be addressed. One helpful measure, it says, is the $\mathfrak{E} 60$ million (US\$97 million) 'University Challenge' fund set up by the government, the trust and the Gatsby Foundation to help universities commercialize their research.

The audit analysed 322 neuroscience research papers cited in 371 US patents. Three quarters of papers were basic research as opposed to clinical studies. Britain's 110 named inventors came second only to the United States, which dominated with 561. France had 50, Japan 29, Italy 20; Germany came third from bottom with two inventors.

Researchers from the United States dominate eight subfields in neuroscience by publishing around 50 per cent of papers in basic research and 60 per cent of clinical studies. Britain, however, is the only country whose share of research is steadily increasing in most neuroscience subfields.

Neuroscience research represents currently 16 per cent of the 227,000 papers in biomedicine published annually around the world. 